\title{
Corpo, festa e ludicidade: a cultura maringaense retratada em telas ${ }^{1}$
}

\author{
Fabiane Castilho Teixeira ${ }^{1}$ \\ Larissa Michelle Lara ${ }^{2}$ \\ leda Parra Barbosa Rinaldi ${ }^{2}$ \\ ${ }^{1}$ Mestranda do Programa de Pós-graduação Associado em Educação Física UEM/UEL, \\ $P R$, Brasil \\ ${ }^{2}$ Departamento de Educação Física da Universidade Estadual de Maringá, Grupo de \\ Pesquisa Corpo, Cultura e Ludicidade da UEM, Maringá, PR, Brasil/CNPq
}

\begin{abstract}
Resumo: $O$ texto analisa como corpo, festa e ludicidade aparecem na pintura em telas da artista plástica Lilia Lobo e como sua arte traduz a memória cultural da cidade de Maringá-PR. Com base no método iconológico, o intuito do estudo é apresentar obras que retratam a cultura nesta cidade, notadamente, aquelas que tematizam as festas. Os dados atentam para a materialização imagética da cultura maringaense, ressaltada em detalhes que expressam um corpo lúdico num campo festivo singular. As investigações apontam para a necessidade de contribuir para a difusão/valorização de artistas que se tornam esquecidos e que produzem importante documento iconográfico da cultura da cidade.
\end{abstract}

Palavras-chave: Corpo. Cultura. Educação Física.

\section{Body, party and ludic way: the Maringá culture reported in paintings}

\begin{abstract}
The text analyses how body, party and ludic way appear in the oil painting of the artist Lilia Lobo and how her art translate the Maringá city, Paraná state, cultural memory. Using the iconological method, the purpose of this study is to present a work that reports the culture in this city, mainly the ones that have parties as subject. The data focus the imagnetic materialization of the Maringá culture, remarked in details that express a ludic body in a singular party field. The investigations point to the need to contribute with a diffusion/valorization of artists that become forgotten and that produce important iconographical documents of the city culture.
\end{abstract}

Key-words: Body. Culture. Physical Education.

\section{Introdução}

A produção artístico-cultural de uma cidade representa a possibilidade de identificação dos protagonistas que interferem em sua dinâmica cotidiana, contribuindo com 0 processo de configuração de sua memória local. Em Maringá, cidade do noroeste do Estado do Paraná com, aproximadamente, 332 mil habitantes, as festas representam espaço de convivência, de celebração da culinária, de música, de danças e, artesanato típicos, bem como de arrecadação de fundos para entidades filantrópicas, setores privados e prefeitura municipal. Embora esta cidade seja lembrada pela poética do compositor mineiro Joubert de Carvalho ${ }^{2}$, há outros traços

\footnotetext{
1 A pesquisa, financiada pela Pró-Reitoria de Pesquisa e PósGraduação da UEM, não poderia ter sido realizada sem a pronta colaboração de Lilia Lobo, que se dispôs a ser protagonista deste estudo, e que muito nos ensinou sobre sua arte. $A$ ela nosso agradecimento especial.

${ }^{2}$ A música Maringá foi escrita pelo compositor Joubert de Carvalho para agradar a um amigo nordestino, e faz referência a Ingá - cidade do nordeste atacada pela seca. A música era ouvida nas vozes dos operários que construíam uma cidade no norte do Paraná, fundada oficialmente em 1947, e que passa a levar esse nome. Cf. MPB CIFRANTIGA. J. C. 31 mar. 2006. Disponível em: <http://cifrantiga3.blogspot.com/2006/03/joubert-de-carvalho.html>. Acesso em 13 fev. 2009
}

identificatórios que evidenciam sua configuração e que são percebidos, neste contexto, pelo tempo-espaço das festas.

As manifestações culturais festivas em Maringá, especialmente aquelas reconhecidas pela comunidade por sua frequente realização, tornaram-se foco de nossas atenções há, aproximadamente, dez anos, como expectadoras, participantes e pesquisadoras. Muitas dessas manifestações, ocorridas em festas, davam-se na forma de apresentações em espaços públicos, sem que as pessoas tivessem que pagar para assisti-las. Isso aconteceu inúmeras vezes em eventos como: Expoingá; Festa Junina da Zona 7; Festa das Nações; Festa Cidade Canção; e Femucic (Festival de Música Cidade Canção).

Em algumas dessas festas, uma artista aparecia como parte do cenário. Trata-se de Lilia Lobo, maringaense, artista plástica que retrata inúmeros eventos representativos da cidade, buscando inspiração no próprio local das festas, retratando ambulantes, artistas populares, dançarinos, barracas, natureza, pessoas e 
músicos. Sua arte seduzia, em especial, pela forma como, gradativamente, dava vida às telas, o que motivou o estudo de sua produção.

A escolha das categorias corpo, festa e ludicidade deu-se por elas integrarem nossas investigações junto à educação física. Tais categorias apresentam suas características e especificidades, visualizando a tela como um cenário de cores, formas e conteúdos, cujos traços não se encontram estanques. Daí objetivarmos entender como estas categorias aparecem projetadas na cultura maringaense a partir das telas da artista e como suas obras traduzem parte da memória festiva da cidade.

Os primeiros contatos com Lilia iniciaram-se no ano de 2006, quando fizemos o convite para a pesquisa e obtivemos seu consentimento ${ }^{3}$. Foram feitas visitas constantes à sua casa para conversas e entrevistas, ao mesmo tempo em que se dava o reconhecimento de suas obras por meio de observações participantes e registros fotográficos. $\mathrm{Na}$ pesquisa, as telas foram analisadas e a apreciação da estética da artista aparece representada. $O$ texto propõe-se a apresentar as telas, discutindo como o corpo é tratado, como se percebem elementos lúdicos e como a cultura maringaense é visualizada.

O método iconológico foi escolhido para o desenvolvimento da pesquisa e consiste em três etapas, de acordo com Panofsky (1989): a) préiconografia, caracterizada pela identificação dos motivos artísticos e experiência empírica; b) iconografia, que busca a descrição das imagens, histórias e alegorias, relacionando-as a fontes literárias; c) fase iconológica, constituída pela síntese a partir do mundo de valores simbólicos. Assim, o tratamento dos dados da pesquisa foi realizado mediante as técnicas próprias da iconologia, que se traduzem pela focalização das informações ligadas diretamente às categorias elegidas (acima relacionadas), pelas descrições, interpretações e análises das telas feitas pelas pesquisadoras, bem como pela relação estabelecida com a literatura no que se refere ao corpo, à cultura e à ludicidade.

A análise das imagens, no entendimento de Silva (2005), requer a observância a dois momentos básicos: dar tempo ao diálogo e também se expor a esse diálogo, pois o que

\footnotetext{
${ }^{3}$ O estudo foi aprovado pelo COPEP - Comitê de Pesquisa e Ética com Seres Humanos da Universidade Estadual de Maringá - Parecer n. 202/2006.
}

parece indecifrável à primeira vista começa a ganhar sentido com o tempo. Para descrever algo é necessário saber cada detalhe na composição do todo por meio de um estudo minucioso da produção imagética, seja ela um quadro, uma fotografia, uma capa de revista ou outra imagem. O primeiro passo desse processo é a descrição, seguido da análise dos períodos vinculados à imagem, buscando-se informações sobre a sua fonte e as suas diferentes perspectivas.

O texto em questão volta-se para a análise de como corpo, festa e ludicidade aparecem na pintura em telas da artista plástica Lilia Lobo e como sua arte traduz a memória cultural da cidade de Maringá-PR. Na primeira parte são realizadas incursões pelas categorias eleitas, situando-as no estudo. $\mathrm{Na}$ segunda, são realizadas descrições das telas da artista plástica Lilia Lobo, localizando-as no campo festivo da cidade de Maringá, bem como análises que associam as categorias eleitas às telas da artista.

\section{Corpo, festa e ludicidade: arriscando alguns riscos}

Buscar caminhos para o entendimento do corpo, da festa e da ludicidade representou alguns desafios, principalmente pela vasta possibilidade de fazê-lo por meio de correntes teóricas diversas. Entretanto, não é nosso intuito elencar tais correntes, mas trabalhar com compreensões que, direta ou indiretamente, nos instiguem a entender como elas podem ser percebidas a partir da documentação imagética.

Ao estudar o corpo como construção cultural, Siebert (1995, p. 34) entende que ele não pode ser pensado sem a ação do homem no mundo quando gera sensações, emoções e imagens. "A cultura é importante determinante da maneira como o corpo vai se expressar, pois é preciso que se compreenda o sentido/significado que têm essas práticas corporais para a comunidade que as vive." O corpo é o meio pelo qual o homem se expressa, vive e comunica-se com o mundo, revelado em suas contradições.

Como acontecer apolíneo e dionisíaco - ordem e caos - o corpo alcança os (des)equilíbrios. É mutação, desejo de ir e vir. É templo desabitado, expressão cartesiana; liberdade que ruma à totalidade. Recanto de virtudes e pudores, mas também de vícios e transgressões, o corpo é acontecimento, história, movimento, sentido ético-estético (LARA, 2004, p.60).

O corpo constitui-se como mosaico, cuja 
diversidade, tanto quanto suas tensões contrastantes, expressam sua singularidade. É essa constituição como objetivo heterogêneo e plural, adverte Sant'Anna (1995), que admite diversificadas bases culturais, numa rede interminável de conhecimento.

Como fenômeno historicamente situado e inacabado, o corpo é foco de desejos, tanto numa concepção essencialmente "humana" quanto nos moldes instrumentais/capitalistas. Busca ser ressignificado, tendo na festa um desses espaços. Neste contexto festivo, pode libertar-se momentaneamente dos padrões e normas sociais, desfrutando de prazer e diversão, pois a ludicidade, sendo categoricamente uma dimensão que permeia o fenômeno festivo, pode atribuir novos significados ao corpo.

Tais reflexões conduzem-nos a indagar: Por que a festa pode atuar como regeneradora do sujeito? Por que em alguns momentos os seres humanos carecem do tempo-espaço da festa? Talvez, seja justamente porque a festa é um tempo-espaço de ruptura com a rotina cotidiana, um acontecer diferenciado, capaz de extrapolar regras que regem a vida social humana, já que essa, como lembra Brandão (1989), toma para si os mesmos sujeitos e objetos, quase a mesma estrutura das relações da vida cotidiana, e os transfigura. A festa se apossa da rotina e excede sua lógica, cedendo lugar ao breve ritual de transgressão. Contudo, até mesmo essas experiências diferenciadas podem suportar grande carga de interesses, valores e símbolos que foram historicamente adquiridos e que são culturalmente propagados, uma vez que os espetáculos festivos não expressam somente sua faceta encantadora, mas mesclam-se com as imposições dos modismos, do mercado e do consumo.

Como lembra Caillois (1988), embora a festa traga o paroxismo social, o convite para ela nem sempre é inocente. Seu sentido/significado agrega o desejo de realizar e o de arrecadar, o de renovar e o de instrumentalizar, o de fruir e o de consumir. Mesmo assim, a festa coloca-se como o ensejo de ruptura, de ingresso num tempoespaço diferenciado, próprio, em que o dionisíaco pode ser rememorado como potência de vida.

As pessoas buscam, nesse tempo-espaço próprio, substituir as ações institucionalizadas que são rotuladas pelo sistema social por ações simbólicas, representativas e lúdicas, sendo que essas demarcam a possibilidade de criação de figuras, podendo, dessa maneira, assumir novos papeis, muitas vezes, não potencializados em sua imaginação. Contudo, até mesmo essas experiências diferenciadas podem suportar grande carga de interesses, valores e símbolos que foram adquiridos e que são culturalmente propagados, uma vez que os espetáculos festivos não expressam somente sua faceta encantadora, mas se mesclam às imposições dos modismos, do mercado e do consumo. Como adverte Rosa (2002, p.37), não se deve generalizar os comportamentos $e$ os interesses que se manifestam na festa, pois a cultura não é algo estático, mas apresenta contradições em seu contexto.

Tomando por base essa perspectiva, o lúdico torna-se elemento essencial do fenômeno festivo, uma vez que a festa configura-se como complexo acontecimento da realidade sociocultural. O predomínio da alegria, a revelação de sentimentos, a presença dos desejos, da imaginação, da sensibilidade que compõem o tempo-espaço da festa demonstram que o lúdico aparece como estado motivacional que desencadeia a capacidade das pessoas de sair da rotina para transgredir suas normais condutas. O lúdico configura-se como acontecer de caráter subjetivo, desvinculado de fatores produtivos, embora não dissociado das dimensões racionais da vida humana. É, nos dizeres de Debortoli (1999), dimensão da linguagem humana, possibilidade de expressão do sujeito criador, daquele que é capaz de dar significado à sua existência.

O lúdico caracteriza-se pela alegria, satisfação, prazer e motivação, bem como pela ruptura com as obrigações da vida cotidiana. Contudo, não se pode considerar que o lazer (como manifestação cultural) e o lúdico (como uma de suas possibilidades) estejam descompromissados com as esferas sociais. Ocorrem em um momento de desobrigação momentânea, conforme Pimentel, Pimentel (2006). Mas isto não significa que não sejam ações sérias, relevantes, pois pensar 0 lazer/lúdico como totalmente antagônico ao trabalho é disseminar a dicotomia que se faz presente entre essas dimensões da realidade, que entende o trabalho como um fazer produtivo e responsável e as experiências de lazer como acontecimentos improdutivos e inoportunos. 
No âmbito das comemorações festivas, o corpo lúdico aparece como parte fundante do cenário. Seja na dinâmica da própria festa ou materializado num tempo suspenso, como nas telas, o corpo lúdico é observado. Ele é capaz de trazer o significado da festa em seu sentido primeiro, qual seja, o de comungar, possibilitar fruição, provocar paroxismos, levar ao dionisíaco, instalar uma (des)ordem criadora e reveladora do sujeito em sua condição humana. Assim, é essa caracterização que se coloca como ponto de interesse pela iconografia de Lilia Lobo, em especial, pela temática festa, cujos personagens, instante próprio, cenários, delineiam traços identificatórios e peculiares de um dado contexto social.

\section{A cultura maringaense em Lilia Lobo}

Lilia Lobo nasceu em Maringá-PR, no ano de 1956, e morou com sua família até os 26 anos de idade. Na infância, não podia brincar em outro local que não fosse sua casa, pois seus pais eram muito severos. O mesmo acontecia no ambiente escolar. Não se recorda de brincadeiras, tampouco de amigos. Conforme a artista, apesar da imensa dificuldade que tinha com as disciplinas, em desenho, sempre se destacou.

O envolvimento com a pintura deu-se na juventude e, de forma ocasional, quando se deparou com a oferta de um curso para formação de artistas plásticos. Inscreveu-se e, logo, já estava realizando pintura em telas. Entretanto, sua arte não a encantava e nem lhe era fonte de criação, o que a levou a buscar formas inspiradoras. Começou com pintura primitiva em objetos pequenos - caixinhas de fósforos e folhas de calendários - e, paulatinamente, foi dando conta de preencher telas maiores. Há 20 anos pinta natureza, pessoas, animais e, por meio de contornos minuciosos, dá vida às telas.

A inserção de Lilia no tempo-espaço das festas deu-se quando, em 1999, ela foi convidada a participar de uma Feira de Exposição (Expoingá) para retratá-la. Durante três dias pintou um quadro que, segundo ela, nada tinha a ver com o evento. Começou a desenhar os componentes da festa que mais lhe chamavam atenção e, foi a partir de então, que esse tema se tornou fonte de inspiração.

A artista não representa, nas telas, a realidade da festa de forma idêntica, mas atribui a elas sua criação. Entende que a arte não pode advir de uma cópia, mas das expressões do artista, sempre permeadas por fontes de inspiração. Suas telas nascem no campo festivo, mas nem sempre são concluídas nele, pois, segundo Lilia, só finaliza uma tela quando sua inspiração e criação dão conta de representar minuciosamente os detalhes que compõem a festa. Para a artista plástica, o sentido de pintar festas está no fato de dar diversão e alegria à sua vida.

A análise das obras de Lilia Lobo sobre festas revela a multiplicidade de elementos que constituem um tempo-espaço próprio. Das 50 telas sobre festas, nove foram selecionadas para investigação: duas da Expoingá; duas das Festas das Nações; uma obra da Festa Cidade Canção; duas referentes à Festa Junina da Zona 7; e duas do Femucic.

As telas com o tema Expoingá foram pintadas entre 1999 e 2002. Essa é uma tradicional festa maringaense que ocorre, anualmente, no início do mês de maio, desde 1972, no Parque Internacional de Exposições Francisco Feio Ribeiro. É uma das mais reconhecidas exposições agropecuárias do Sul do país e a organização do evento fica a cargo da Sociedade Rural de Maringá (SRM) - núcleo de empresários rurais que se dedicam à administração do parque e promoções de eventos voltados para a difusão de gados de todas as raças e tecnologias.

A artista relata que pintar a Expoingá, de 1999, possui um significado importante para seu trabalho, pois foi a primeira vez que retratou um evento festivo a partir de sua inserção no local. Para ela, essa forma de produzir arte contribuiu no sentido de tornar sua pintura criativa, vivaz e espontânea.

Em relação à tela da Expoingá de 2002, Lilia salienta que a constituição da festa mudou no sentido de se ter outros acontecimentos, mas a participação dos expectadores se manteve de forma idêntica. Isso porque as pessoas buscavam conhecer coisas novas, prestigiar as apresentações da festa, ter um momento de diversão com a família, com os amigos, descansar depois de um dia exaustivo no trabalho, assim como ocorreu na primeira Expoingá que ela pintou. Segue figura 1, com duas telas sobre o tema.

Na tela sobre a Expoingá, de 1999, a artista plástica retrata $o$ parque de diversões e seus elementos constituintes, como bilheteria, arena de 
rodeio, vendedor de bexigas, músicos, natureza, touro mecânico, esquadrilha da fumaça, ônibus, empresa rodoviária, brinquedos (como carrossel e montanha russa), balões, avestruzes gigantes, helicóptero (que podem advir de suas criações ou não), entre outros componentes. As pessoas aparecem ora montadas nos brinquedos, ora observando-os. Percebemos homens, mulheres, crianças, casais, famílias inteiras, que foram dispostos na tela em meio às atrações do parque.

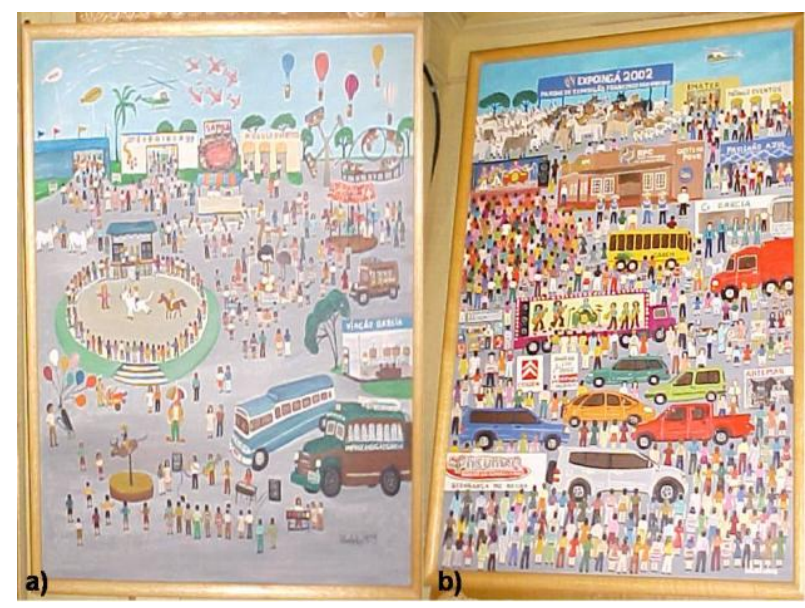

Figura 1. a) Expoingá (1999); b) Expoingá (2002). Fotografias: Fabiane Castilho Teixeira; Telas: Lilia Lobo.

A tela referente à Expoingá, de 2002, foi retratada pela artista, notadamente, a partir dos expectadores que se inseriram no evento. As pessoas aparecem, em sua maioria, de costas, como que prestigiando as apresentações artísticas. São representadas em meio a várias figuras, até mesmo meios de transporte com logomarcas das empresas que Lilia se dispôs a pintar. É interessante notar que, diferentemente da Expoingá, de 1999, nessa obra, a artista não deu ênfase ao parque de diversões, sempre presente em tal evento. Contudo, traz um número maior de pessoas que aparecem assistindo as bandas, observando os animais e as exposições de artes, dirigindo-se ao pavilhão azul (local em que artistas famosos realizam shows).

As obras sobre a Festa das Nações foram pintadas entre 1999 e 2004. Trata-se de uma das mais importantes festas gastronômicas da cidade, que vem sendo realizada desde 1983. A promoção fica a cargo da Prefeitura de Maringá e de 22 entidades assistenciais. É intitulada Festa dos Estados e das Nações, e Feira de Artesanato, porque as entidades participantes são identificadas com nome de um Estado ou uma Nação e servem pratos típicos que representem suas escolhas. Além disso, são apresentadas atrações folclóricas durante o evento.

Lilia Lobo revela que foi desafiador pintar a Festa das Nações, de 1999, sobretudo porque se trata do segundo evento retratado por ela a partir de seu ingresso no local das festas. A nova maneira de produzir sua arte trouxe lhe certo estranhamento e dificuldade (principalmente para preencher a tela), mas isso a instigava ainda mais a pintar. "Esse quadro é muito bonito, mas não favorece a comemoração em si. Faltou colocar as barracas de comidas típicas que são características da Festa das Nações" 4.

Já em relação à festa realizada no ano de 2004, (no mesmo local), Lilia acredita ter dado conta de registrar melhor os acontecimentos e personagens que faziam parte do campo festivo. Nos relatos sobre essa tela, Lilia mostra-se preocupada em enfatizar uma questão: todas as obras sobre as tradicionais festas maringaenses são permeadas de seus reais acontecimentos, ao passo que suas atribuições artísticas se fazem sempre presentes. E afirma: "As noivas ao redor da Catedral não compõem a Festa das Nações, mas aparecem em todos os meus quadros sobre essa festa, pois, para mim, as obras não ficariam completas e, tampouco me sentiria realizada se não as colocasse ali" ${ }^{5}$. Essa ideia apresentada por Lilia atrela-se ao fato de ser prática comum a aglomeração de noivas vestidas a caráter no gramado da Catedral para tirar fotos. Até mesmo as que não casam nesta cidade, mas em localidades próximas, deslocam-se até lá com essa finalidade. Segue Figura 2 com a representação da Festa das Nações, tradicionalmente ocorrida em frente à catedral.

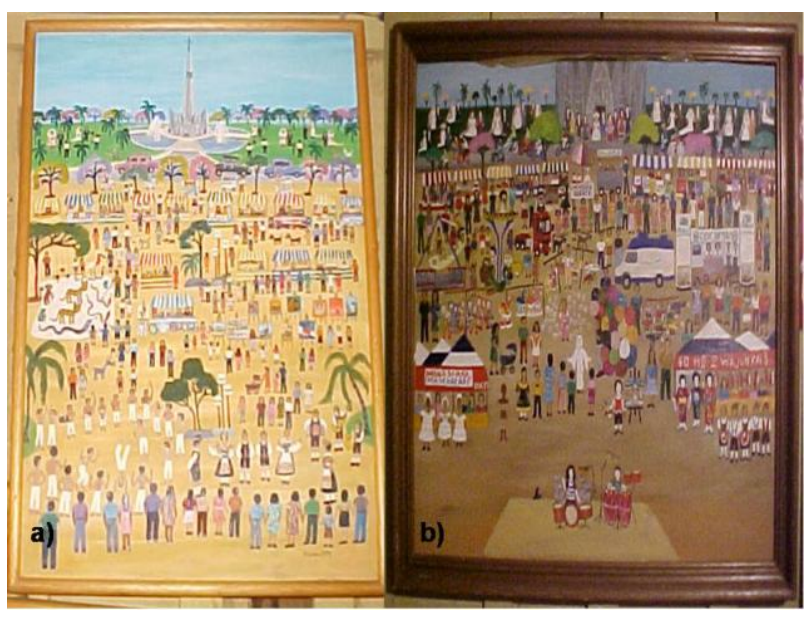

Figura 2. a) Festa das Nações (1999); b) Festa das Nações (2004). Fotografias: Fabiane Castilho Teixeira; Telas: Lilia Lobo.

\footnotetext{
${ }^{4}$ Entrevista concedida por LOBO, Lilia. Maringá, 30 abril 2007.

5 Ibid.
} 
A tela sobre a Festa das Nações, de 1999, apresenta diversos componentes. Aparecem personagens festivos (expectadores, grupos de danças, músicos, artistas e capoeiristas), barracas de artesãos, árvores, animais, lustres na praça, automóveis na rua, noivas em volta da Catedral de Maringá (ao fundo), entre outros. Dentre as manifestações corporais presentes estão a capoeira (vários capoeiristas jogam e tocam instrumentos) e a dança alemã.

A tela referente à Festa das Nações, de 2004, evidencia a Catedral, figura marcante das obras sobre essa festa, representada na parte superior da tela, com os casais de noivos em seu entorno. Os expectadores, ambulantes e artistas estão, em sua maioria, pintados com os rostos de frente para Lilia e, até mesmo, como se estivessem posando para ela. Grupos de dança alemã, japonesas, baianas, barracas de comidas (churros e cachorro quente), barracas de artesãos, parque com brinquedos e baleiro são algumas das figuras que dão sentido a essa tela.

Tratando-se da Festa Cidade Canção, Lilia pintou um quadro no ano de 2002, no Centro de Convivência Comunitário da Cidade de Maringá. A tradicional Festa da Canção, que vem sendo realizada desde 1995, conta com barracas para comercialização de comidas típicas e artesanato, além de apresentações culturais, sendo comandada por voluntários e representantes de entidades assistenciais que aproveitam a oportunidade para arrecadar fundos.

Lilia Lobo elucida que o sentido de pintar tal tela se coloca como incompleto. A obra não está concluída porque esse tempo-espaço não the é mais fonte de inspiração como já foi. Segundo a artista, há certa escassez de componentes que atribuam significados à festa, pois faltam elementos que representem verdadeiramente aquilo que o evento festivo se propõe a realizar. A falta de trajes típicos dos diferentes países, bem como a não utilização das vestimentas adequadas nas barracas de músicas são os aspectos mais enfatizados por ela, pois se o próprio cenário festivo não dá conta de demonstrar as particularidades que dão sentido à festa, perde-se o "espírito" de festa.

Como o quadro que retrata a Festa da Cidade Canção, de 2002, ainda não está concluído, esse se apresenta com número menor de componentes se equiparado às outras obras de Lilia. A artista retratou, até o momento, algumas barracas com comidas típicas e danças, como o samba e a polca, por exemplo. No fundo há expectadores, um palco com banda realizando sua apresentação, uma roda de capoeira, e prédios da cidade. Consideramos que tal produção de Lilia se constitui num importante elemento para entender o processo de construção de sua arte. $O$ fato de a obra estar inacabada nos remete à percepção de como se dá, nessa tela, o processo de composição. A artista pinta, primeiramente, os elementos no fundo; após, preenche as laterais para, então, transpor as imagens ao centro.

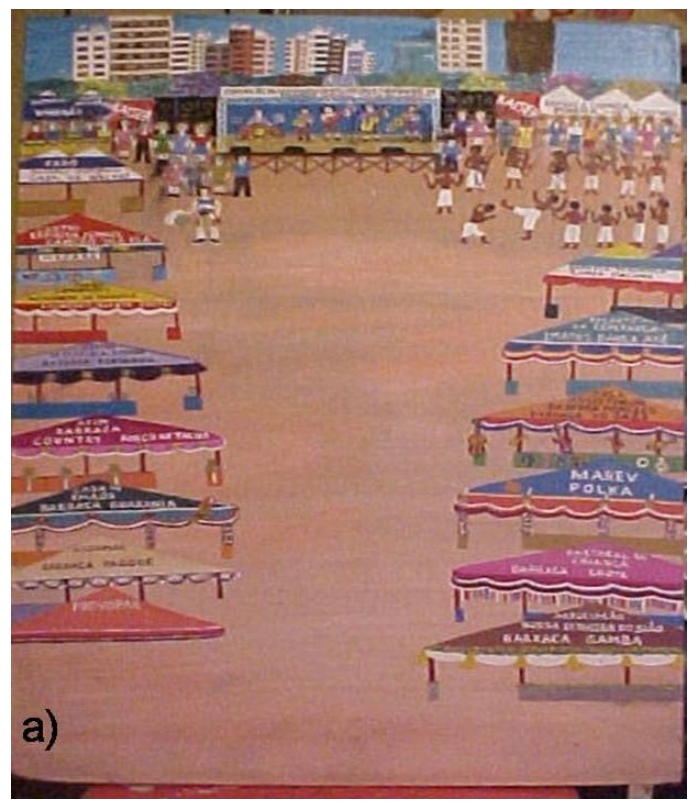

Figura 3. a) Festa Cidade Canção (2002). Fotografia: Fabiane Castilho Teixeira; Tela: Lilia Lobo.

As telas com a temática Festa Junina da Zona 7 foram pintadas em 2000 e 2001. Trata-se de uma tradicional festa da cidade de Maringá, realizada pela Associação Comunitária da Zona 7, nas dependências do pátio do Estádio Willie Davids. O intuito do evento é promover a integração entre as pessoas da comunidade e arrecadar fundos, revertidos a entidades assistenciais e associação de moradores do bairro. Com barracas de comidas típicas e apresentações artísticas, a Festa Junina da Zona 7 reúne não só os moradores do local, mas pessoas de toda a cidade para prestigiar 0 evento.

Conforme Lilia Lobo, pintar a festa de 2000 constituiu experiência interessante à sua profissão de artista plástica. Isso porque, a obra foi produzida numa época que ela pintava personagens bem pequenos, o que demandava, ainda, mais sutileza nos detalhes. Considera que todo artista necessita diversificar e modificar, pois 
"é assim que vive a arte" ${ }^{6}$, das novas experiências que os variados momentos proporcionam.

$\mathrm{Na}$ tela que retrata essa festa, a cidade de Maringá aparece ao fundo, em que se tem a Catedral e os prédios que a compõem. A apresentação de dança infantil alemã logo à frente do palco, as barracas de comidas típicas de festa junina e a quadrilha com o casal de noivos ao centro da roda são alguns componentes que chamam atenção nessa tela.

Em relação à festa de 2001 , a artista relata que esperava encontrar inúmeros elementos com os quais pudesse trabalhar. Porém, no primeiro dia de festa percebeu um cenário "morto", com poucos componentes festivos. Assim, foi necessário aguçar seu potencial criativo já que o contexto não lhe proporcionou inspiração.

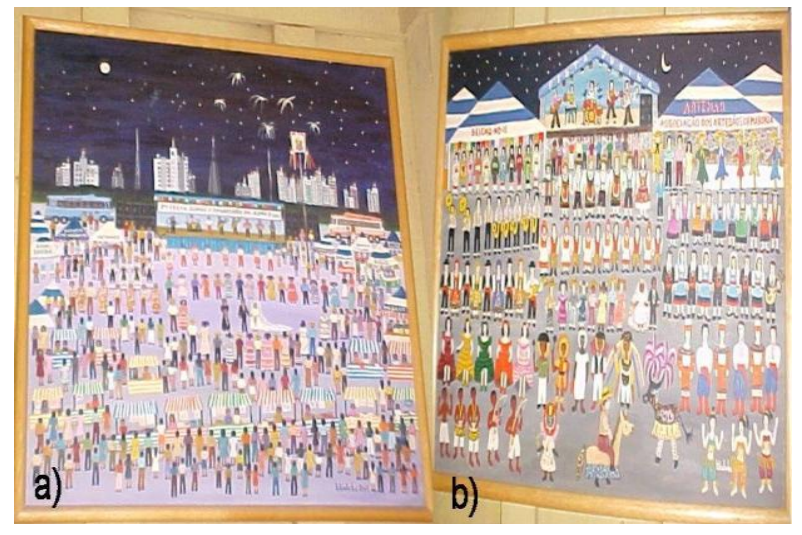

Figura 4. a) Festa Junina da Zona 7 (2000); b) Festa Junina da Zona 7 (2001). Fotografias: Fabiane Castilho Teixeira; Telas: Lilia Lobo.

Na tela sobre a Festa Junina da Zona 7, de 2001, são notórias as diferenças entre a pintura que a artista realizou e a que fez em ano anterior. $\mathrm{Na}$ de 2001, dá ênfase às apresentações de músicos e grupos folclóricos, uma vez que as barracas e os expectadores não se colocam como elementos centrais de sua produção. Aparecem representados as bandas musicais, a barraca japonesa da Seicho-No-le, os grupos de danças alemã, italiana, portuguesa, espanhola, ucraniana, a dança do ventre, os capoeiristas, a quadrilha com o casamento caipira e o bumbameu-boi, tradicionais na cultura maringaense.

As telas com a temática Femucic foram pintadas entre 2004 e 2006. O Femucic (Festival de Música Cidade Canção) é um festival nacional que ocorre na cidade de Maringá-PR, criado em 1977, como um pequeno movimento musical, e hoje, atrai músicos, cantores e compositores de

${ }^{6}$ Entrevista concedida por LOBO, Lilia. Maringá, 16 jun. 2007. 412 várias partes do país. O evento é promovido pela Prefeitura de Maringá (Secretaria de Cultura), pelo Sesc (Serviço Social do Comércio) e pela TV Cultura (Rede Paranaense de Comunicação).

Segundo Lilia, num primeiro momento, o que a motivou a participar do Femucic, realizado em 2004, no teatro Calil Haddad, foi a necessidade de divulgar seu trabalho. $O$ fato de reunir artistas de diferentes localidades do país e atrair a imprensa ajudaria a se tornar mais conhecida no meio artístico. Contudo, o evento, para ela, superou essa necessidade inicial. Afirma que aquele contexto possibilitou que registrasse fielmente os personagens como se apresentaram.

Já em relação à festa realizada no ano de 2006, a artista salienta ter sido sua pintura menos diversificada se relacionada às apresentações musicais características da festa.

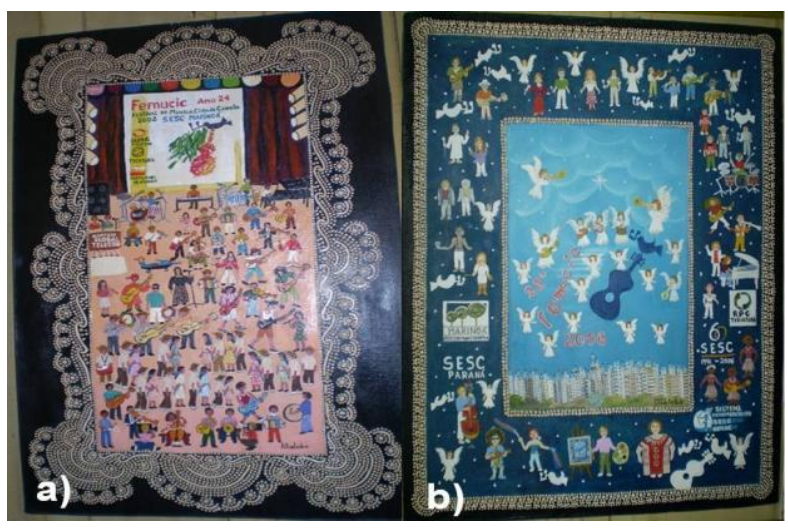

Figura 5. a) Femucic (2004); b) Femucic (2006). Fotografias: Fabiane Castilho Teixeira; Telas: Lilia Lobo.

A tela sobre o Femucic, de 2004, apresenta quadrilha, conjunto de violeiros, empresas que patrocinaram a festa e rapaz rolando sobre o skate, figuras que se mesclam aos diversos músicos e seus instrumentos, compondo a tela. Aparecem guitarristas, pianistas, bateristas, sanfoneiros, violinistas e cantores que são sujeitos a atribuir sentido a esse evento.

$\mathrm{Na}$ tela do Femucic, de 2006, banda, músicos, instrumentos, personagens excêntricos, como o rapaz com cabelo estilo black power tocando viola e demais componentes, foram pintados como se o cenário festivo se desse no âmbito de um céu estrelado, o que se coloca como outra forma de perceber a constituição da festa.

As investigações realizadas nas obras da artista plástica Lilia Lobo se deram por meio de olhares atenciosos, permeados por estudos que efetuamos, pela literatura a qual recorremos e por nossa subjetividade, isto é, pelas percepções e 
sensações que obtivemos em contato com sua arte. Os diferentes personagens que compõem as telas são representados em sua simbologia corpórea, em sua dinâmica, mesmo representados estaticamente.

A exemplo do que nos trouxe Rosa (2002), a festa se dá num ambiente sociocultural em que se projetam cenários, personagens, palco, local. O excêntrico, um dos fenômenos festivos, indica a transgressão das próprias limitações da festa, 0 rompimento com algumas regras. Essa peculiaridade das manifestações festivas é subjetiva e, também, objetivamente demonstrada na arte de Lilia, uma vez que, em suas telas, os personagens assumem diferentes papeis no âmbito dessas comemorações, revelando um lócus capaz de transgressões.

Os diferentes corpos apresentados por Lilia, apesar da diversidade étnica e sócio-econômica, parecem imbuídos dos mesmos sentimentos de festa, uma vez que demonstram ter ingressado no campo festivo em busca de novas experiências, de um tempo-espaço diferenciado que possibilite renovar e recrear, e que torne a diversão autorizada. Além disso, os personagens mostramse orientados pelo lúdico, que também imprime suas marcas, pois efetiva momentos de prazer, contentamento e divertimento, e como dimensão humana, abre espaço à expressão dos sujeitos.

\section{Situando os eixos de análise}

Tomando por foco o referencial teórico utilizado no desenvolvimento desse estudo e a pesquisa obtida em campo, podemos elencar quatro eixos de análise, o que explicitaremos.

O primeiro eixo entende que Corpo, cultura e ludicidade são categorias essencialmente presentes no campo festivo. O corpo, meio de expressão dos sujeitos, é fundamentalmente a dimensão que atribui sentido/significado ao contexto das festas, possibilitando a comunicação entre as pessoas e a interação com o ambiente festivo. As relações percebidas nas telas levam a visualizar o corpo, sua linguagem e movimento, entendendo que esse fenômeno participa de um sistema simbólico que permeia todas as ações humanas.

As práticas corporais próprias das festas não são impermeáveis às marcas da cultura, considerando essa uma dimensão que instaura significados particulares às mais diversas atuações do homem. O corpo festivo apresenta condições de libertar-se das normalizações que regem o meio social, pois a festa abre espaço às manifestações lúdicas, a uma diversão autorizada, aos momentos de prazer e contentamento. A presença do lúdico no contexto festivo possibilita que novos significados sejam atribuídos às representações do corpo. Com base nas investigações sobre festas é possível perceber que corpo, cultura e ludicidade são dimensões que, fundamentalmente, permeiam o âmbito dessas manifestações.

Nas telas de Lilia Lobo, corpo, cultura e ludicidade são fenômenos relacionados e em completa dinamicidade. Este eixo atenta para o fato da iconografia da artista estar imbuída das percepções que ela tem em contato com o ambiente festivo. Podemos considerar, então, que os corpos configurados em suas telas emergem de determinado contexto social e estão condicionados às suas influências. A cultura, como campo simbólico, instaura um sistema de representações.

O corpo festivo (apresentado na pintura em telas) mostra-se orientado por determinantes de caráter sociocultural (comportamentos, valores, costumes e interesses). $\mathrm{Na}$ festa, o corpo pode libertar-se dos padrões e desfrutar de momentos de prazer e diversão, pois a ludicidade é capaz de Ihe atribuir novos significados. As imagens criadas/representadas por Lilia nos remetem a reflexões acerca das relações que se estabelecem entre as manifestações do corpo, as influências de ordem cultural e as possibilidades lúdicas.

O terceiro eixo aponta que $O$ corpo, a festa, a cultura e a ludicidade são retratados a partir de uma realidade objetiva/subjetiva da artista. As imagens reveladas nas obras de Lilia Lobo provêm da sua capacidade de buscar inspiração no próprio local das festas. Os inúmeros personagens e diferentes cenários são, em sua maioria, registrados, porque fazem parte da memória da artista. Isso significa que Lilia toma por foco suas reais percepções no desenvolvimento das telas. Entretanto, faz-se possível perceber que as criações e atribuições da artista estão presentes, ainda mais ao colocar em seu trabalho interesses e buscas, criando elementos que, por vezes, não compõem os eventos que participa.

Por fim, o último eixo apresenta a ideia de que As obras de Lilia Lobo que tematizam as 
tradicionais festas maringaenses se colocam como importantes registros da cultura da cidade. $\mathrm{Na}$ iconografia da artista plástica, a representação do corpo na festa e sua simbologia lúdica fazem de seu trabalho importante documento iconográfico da cultura de Maringá. A capacidade da artista de buscar inspiração no instante da festa e traduzir suas percepções em imagens torna sua arte retrato vivaz de inúmeros eventos representativos da cidade, memória de sua gente, de seus artistas anônimos e de sua pluralidade.

A iconografia da artista apresenta as práticas corporais e seus condicionantes. Sua arte, ao revelar as múltiplas facetas do corpo, da festa e da ludicidade, abre-se a inúmeras maneiras do corpo se expressar, seus signos, linguagens e movimento, assim como os determinantes que 0 condicionam. As obras sugerem a exploração de temáticas como lazer, tempo livre, danças, música, arte, brincadeiras populares, festas, cultura, etnias, gerações, cidade e indústria cultural. As telas, como arte, incitam às mais diferenciadas possibilidades de leitura e discussão, o que torna o aprendizado construído de modo dialogado bastante atrativo ao processo de formação do aluno.

\section{Considerações finais}

Esse texto, resultado de pesquisa científica realizada entre os anos de 2006 a 2008, objetivou apresentar como as categorias corpo, festa e ludicidade aparecem em obras da artista plástica Lilia Lobo, especificamente, as que têm por tema a festa. Procuramos entender como se dá a inserção de Lilia nas festas e, ainda, como suas obras se traduzem em parte da memória de Maringá.

Os dados nos levam a perceber que corpo, cultura e ludicidade são categorias essencialmente identificadoras das telas de Lilia Lobo, retratados nos personagens que compõem as obras, nos cenários, na multiplicidade de cores/formas que as constituem. Na iconografia da artista, o corpo dança, brinca, canta, divertese, trabalha, come e compra, ingressando num tempo-espaço que o retira de seu cotidiano, por vezes, rotineiro e desestimulante, para se inserir num tempo-espaço diferenciado, em que novas regras de ordem sociocultural podem ser estabelecidas.

Cabe salientar que não é intenção de Lilia trabalhar as relações existentes entre corpo, cultura e ludicidade. As reflexões acerca de tais categorias advêm de nossas investigações das obras sobre festas, uma vez que percebemos que, mesmo sem intencionalidade, a artista produz rico acervo que possibilita tais associações.

Apesar da artista registrar parte da memória de Maringá, sua arte torna-se esquecida em meio a de tantos outros artistas, justamente porque vivemos em uma época em que atribuímos valor, unicamente, às dimensões instrumentais da vida humana, esquecendo que o homem não vive somente de seu mundo racional, técnico e instrumental, mas necessita também explorar suas sensações, subjetividade, seus interesses, desejos e buscas, no sentido de se tornar um ser pleno, que é capaz de atuar e, até mesmo, transformar a realidade.

Assim, se passássemos a entender e materializar a arte em seu sentido transformador; se a entendêssemos como caminho orientador para a busca de um sujeito não sujeitado, talvez pudéssemos exercer, por meio dela, reflexão crítica e negação de nossa condição desumanizante. Entretanto, isto requer o pleno exercício de entender a arte não como parte restrita de um campo sensível ou fonte menor de conhecimento, mas como regeneradora da própria condição humana, como expressão de uma "outra" racionalidade desejosa de reconhecimento e valorização, como potencial revolucionário da arte de educar.

\section{Referências}

BRANDÃO, C. R. A cultura na rua. Campinas: Papirus, 1989.

CAILLOIS, R. O homem e o sagrado. Lisboa: Edições 70, 1988.

DEBORTOLI, J. A. O. Com olhos de crianças: a ludicidade como dimensão fundamental da construção da linguagem e da formação humana. Revista Licere, Belo Horizonte, v.2, n.1, p.105117.1999

MPB CIFRANTIGA. Joubert de Carvalho. 31 mar. 2006. Disponível em: $<$ http://cifrantiga3.blogspot.com/2006/03/joubertde-carvalho.html>. Acesso em: 13 fev. 2009.

LARA, L. M. O sentido ético-estético do corpo na cultura popular. 2004. Tese (Doutorado em Educação) - Faculdade de Educação. 
Universidade Estadual de Campinas, Campinas, 2004.

PANOFSKY, E. O significado nas artes visuais. Lisboa: Presença, 1989.

PIMENTEL, G. G. A.; PIMENTEL, R. M. L.

Questionamento discursivo do lúdico. In:

ENCONTRO NACIONAL DE RECREAÇÃO E

LAZER, 18; ENAREL, 18, 2006, Curitiba. Anais...

Curitiba: PUCPR, 2006.

ROSA, M. C. Festar na cultura. In: ROSA, M. C. (Org); PIMENTEL, G. G. de A.; QUEIRÓS, I. L. von B. G. de. Festa, lazer e cultura. Campinas, SP: Papirus, 2002.

SANT'ANNA, D. B. de (Org.). Políticas do corpo. São Paulo: Estação Liberdade, 1995.

SILVA, A. C. T. da. Uma foto que não era para capa, se prepara para dar a cara à tapa. In: PELEGRINI, S.; ZANIRATO, S. H. (Org.).

Dimensões da imagem: interfaces teóricas e metodológicas. Maringá: EDUEM, 2005. p.39-52.

SIEBERT, R. S. S. As relações de saber-poder sobre o corpo. In: ROMERO, Elaine (Org.).

Corpo, mulher e sociedade. Campinas, SP: Papirus, 1995.

Endereço:

leda Parra Barbosa Rinaldi

Departamento de Educação Física da UEM

Rua Argentino Moreschi, 396

Maringá PR Brasil

87080-127

Telefone: (44) 3028.5962 ou (44) 8404.9635

e-mail: parrarinaldi@hotmail.com

Recebido em: 31 de maio de 2010.

Aceito em: 11 de março de 2011.

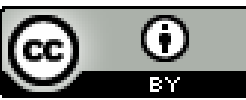

Motriz. Revista de Educação Física. UNESP, Rio Claro, SP, Brasil - elSSN: 1980-6574 - está licenciada sob Creative Commons - Atribuição 3.0 